\title{
COMPETIÇÃO HACKAHOME ENTRE RAMOS ESTUDANTIS IEEE PARA PROJETOS COM SOLUÇÕES PARA TRANSIÇÃO DA APLICAÇÃO PRESENCIAL PARA A REMOTA PERANTE DISTANCIAMENTO SOCIAL
}

DOI: 10.37702/2175-957X.COBENGE.2021.3590

Mariana Larissa Antunes da Costa - mariana.antunes@engenharia.ufjf.br Universidade Federal de Juiz de Fora

Praca do Cruzeiro 42

36016-260 - Juiz de Fora - MG

Dalila Marques Affonso - dalila.marques@engenharia.ufjf.br

Universidade Federal de Juiz de Fora

Rua João Rodrigues Vieira 17

36036-530 - Juiz de Fora - MG

Carlos Alexandre de Almeida Pires - carlos.alexandre@engenharia.ufjf.br Universidade Federal de Juiz de Fora

Rua Doutor Manoel Altomare Nardy 6

37310-000 - Bom Jardim de Minas - MG

Resumo: A atividade HackaHome, desenvolvida pelo Ramo Estudantil IEEE UFJF, surgiu como um método alternativo ao desenvolvimento de projetos realizados por Ramos Estudantis IEEE do Conselho Brasil que precisaram se adaptar ao cenário de distanciamento social devido a pandemia do Covid-19. O HackaHome surge como tentativa de disseminar ideias que possam auxiliar as atividades de voluntariado IEEE no Brasil mesmo em tempos instáveis.

Palavras-chave: Hackathon. IEEE. Desenvolvimento de soluções. Cenário remoto. 


\section{COMPETIÇÃO HACKAHOME ENTRE RAMOS ESTUDANTIS IEEE PARA PROJETOS COM SOLUÇÕES PARA TRANSIÇÃO DA APLICAÇÃO PRESENCIAL PARA A REMOTA PERANTE DISTANCIAMENTO SOCIAL}

\section{INTRODUÇÃO}

O ano de 2020 se tornou um desafio devido ao advento da pandemia do Covid-19. Esta situação obrigou o Brasil e o mundo a adotar novas medidas de prevenção, dentre elas a de distanciamento social que se provou a mais eficaz. Como consequência, a paralisação de atividades educacionais presenciais foi necessária. Sendo assim, a Universidade Federal de Juiz de Fora, assim como outras universidades, suspendeu todas as atividades presenciais a partir do dia 17 de março de 2020. Além disso, as maiores autoridades do IEEE solicitaram, por meio de uma nota divulgada publicamente, que todos os membros evitem realizar atividades presencialmente, a não ser aquelas que são essenciais para o combate à pandemia, e, em vez disso, maximizem o uso de nossas alternativas online e virtuais.

Com isso, os projetos estudantis de todo tipo sofreram um grande impacto e dificuldades para manter suas atividades em andamento de maneira remota. Para os ramos estudantis, a situação não é diferente, forçando-os a se adaptar mesmo sem saber por onde começar. Como forma de driblar essa dificuldade e visando aperfeiçoar a formação dos integrantes de Ramos Estudantis do Conselho Brasil, um determinado Ramo Estudantil IEEE criou o evento HackaHome, uma competição seguindo os moldes de um Hackathon, sendo a dinâmica feita em casa.

O termo Hackathon foi criado a partir da junção de duas palavras da língua inglesa, o "hack" (programar de forma excepcional) e o "marathon" (maratona), dando nome ao evento de programadores e outros profissionais ligados ao desenvolvimento de software para uma maratona de programação presencial, cujo objetivo é desenvolver um software ou solução tecnológica que atenda a um fim específico. Atualmente um Hackathon não se destina exclusivamente para programadores, sua mecânica já é aplicada a vários outros segmentos, com o objetivo de encontrar alternativas ou soluções para problemas.

Sendo assim, o HackaHome vem com a proposta de buscar alternativas e soluções que proponham atividades e projetos que possam ser desenvolvidos completamente à distância, de forma que os ramos estudantis permaneçam operantes.

Visando aperfeiçoar a formação dos integrantes de Ramos Estudantis do Conselho Brasil, procurou-se desenvolver competências que apresentam uma crescente notoriedade no cenário profissional e que, ensinando-as, os participantes teriam um diferencial em seu currículo. Tais competências englobam, como exemplo, a inovação, metodologias ágeis, apresentação/comunicação e criatividade.

O presente trabalho apresentará a metodologia, implementação e resultados do projeto desenvolvido.

\section{METODOLOGIA}

A ideia surgiu a partir do próprio Ramo Estudantil apresentar dificuldades em prosseguir com os projetos e o engajamento dos voluntários durante o período de distanciamento social. Ao perceber esta demanda, a presidente do Ramo Estudantil convidou membros com experiência em inovação para que pudessem organizar um hackathon. Inicialmente, era necessário saber se tal dificuldade era enfrentada por outros 
Ramos Estudantis também. Para isto, foi feita uma pesquisa com lideranças de ramos de todo o Brasil através de mensagens de WhatsApp para validar a proposta e saber do interesse dessas pessoas em participar do evento. A sugestão foi acatada por todos os que responderam ao questionário.

Após esta etapa, planejou-se as atividades e discutiu-se sobre os temas que os projetos poderiam abordar. Foi decidido que as propostas poderiam ter uma ou mais das seguintes frentes: gestão, humanitária, educacional e/ou técnica.

Com o intuito de facilitar e aumentar a visibilidade da iniciativa, foi feito um site exclusivo para o HackaHome, onde estão todas as informações acerca do evento. Os participantes deveriam se inscrever em equipes de até três pessoas através de formulário de inscrição disponível no site, sendo que um mesmo Ramo Estudantil poderia ter mais uma equipe inscrita. A programação do evento foi definida da seguinte forma: o período de inscrições, a semana de atividades em que os participantes teriam capacitações, o prazo para a submissão dos projetos e o dia da divulgação dos resultados. Além do site, o HackaHome foi amplamente divulgado nas redes sociais, como exemplo a Figura 1, do referido Ramo Estudantil e em grupos de WhatsApp.

Figura 1 - Arte de chamada de inscrições nas redes sociais

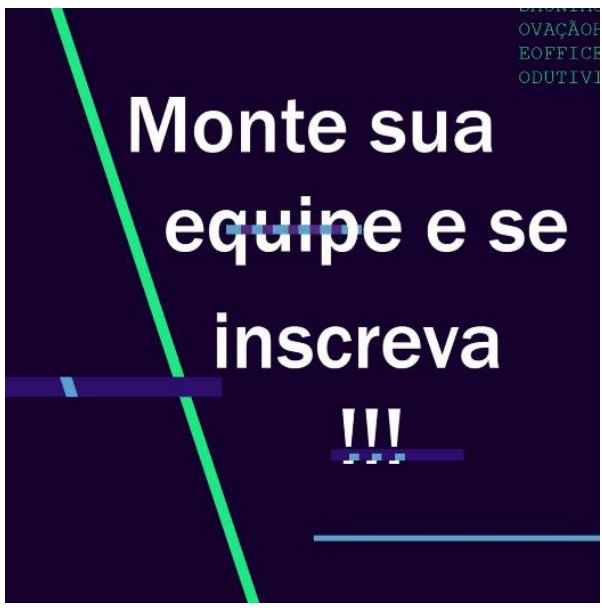

Fonte: Próprio autor 2021

As capacitações citadas acima foram pensadas para ajudar os participantes a estruturarem e desenvolverem sua ideia, mas também de forma que pudesse agregar em suas vidas profissionais e na execução de projetos em seus Ramos Estudantis. Neste sentido, o HackaHome ofereceu workshops de inovação, apresentação pitch, escrita de projetos IEEE e método MVP (Minimum Viable Product, Produto Mínimo Viável em tradução livre). Além disso, foram disponibilizados horários de mentoria para que as equipes pudessem tirar dúvidas. Ao todo, nove mentores disponibilizaram seus horários de atendimento.

As equipes deveriam entregar a proposta em formato de texto descritivo seguindo o template disponibilizado aos participantes e um vídeo de cinco minutos de apresentação pitch do projeto. As propostas foram avaliadas seguindo critérios de avaliação por uma banca multidisciplinar composta por dois membros IEEE e um profissional não membro, que atribuíram a cada competência notas variando de 0 a 100. Cada critério de avaliação teve pesos diferentes na nota final, sendo:

- Inovação: 20 
- Clareza dos documentos: 20

- Viabilidade e aplicabilidade: 25

- Desenvolvimento da ideia: 35

A equipe que conseguiu a maior soma das notas foi a vencedora.

\section{IMPLEMENTAÇÃO}

A situação em que os ramos se encontravam demandava urgência em soluções para o problema da estagnação das atividades. Por este motivo, a organização precisou se apressar para a realização do HackaHome para impactar positivamente durante o período crítico da pandemia. Logo, a divulgação e a execução do evento aconteceram em um período de duas semanas, de forma que os ramos pudessem implementar os projetos propostos o quanto antes.

Quanto às capacitações, a comissão organizadora não se sentia capaz de ministrálas com o domínio que era necessário. Por isso, foi preciso encontrar pessoas com competência e experiência nos temas abordados por esta função. Isto só foi possível devido a rede de contatos que os organizadores possuem. A equipe de facilitadores dos workshops e de mentores foi composta por membros IEEE de outros ramos estudantis do Brasil e por profissionais do mercado.

O custo que o evento poderia gerar segundo seu escopo seria os prêmios para a equipe vencedora. Entretanto, a organização não conseguiu patrocínio em tempo hábil para isto. Então, buscou-se estratégias que possibilitaram um evento de custo zero. A solução encontrada foi oferecer mentorias de carreira como prêmio para as três equipes mais bem avaliadas, ministradas por profissionais voluntários. Desta forma, a premiação foi mais um modo de investir na carreira dos participantes.

A plataforma escolhida para as videoconferências foi o Discord. Entretanto, no primeiro dia apresentou problemas quanto a conexão, pois houve relatos de problemas de qualidade de transmissão por parte dos participantes durante a realização do primeiro workshop, que abordou o tema de inovação, e a abertura do evento. Uma das causas identificadas foi a variação considerável da velocidade da internet entre os que assistiram no momento. Ademais, o esquema de salas que o Discord disponibiliza não atendeu às expectativas do público do evento pois ficaram lotadas e alguns não conseguiram participar da atividade. Diante disso, a apresentação do workshop foi disponibilizada para todos a fim de que fossem minimizados os prejuízos, a abertura do evento foi repetida na plataforma Google Meet em que a conexão foi melhor, e a partir do segundo dia todas as videoconferências foram migradas para o Google Meet.

O problema com a plataforma teve consequências quanto ao calendário, pois algumas equipes confundiram a data de entrega dos trabalhos com a data de divulgação dos resultados. Estas informações haviam sido passadas na abertura do evento que poucas pessoas conseguiram acompanhar. Como tentativa de driblar essa situação, além de repetir a apresentação também foi enviado aos participantes um documento com todas as orientações gerais e etapas do HackaHome. Todos foram adicionados também a uma agenda que continha toda a programação, entretanto esta medida não se provou suficientemente eficiente.

\section{RESULTADOS}

Das doze equipes inscritas, nove entregaram o seu escopo de projeto na data determinada e destes todos apresentaram ideias com alto grau de inovação e criatividade, 
assim como esperado de uma competição como esta. Tal argumento pode ser verificado pela média geral das notas de cada competência avaliada como o Gráfico 1.

Gráfico 1 - Média das notas dos projetos entregues

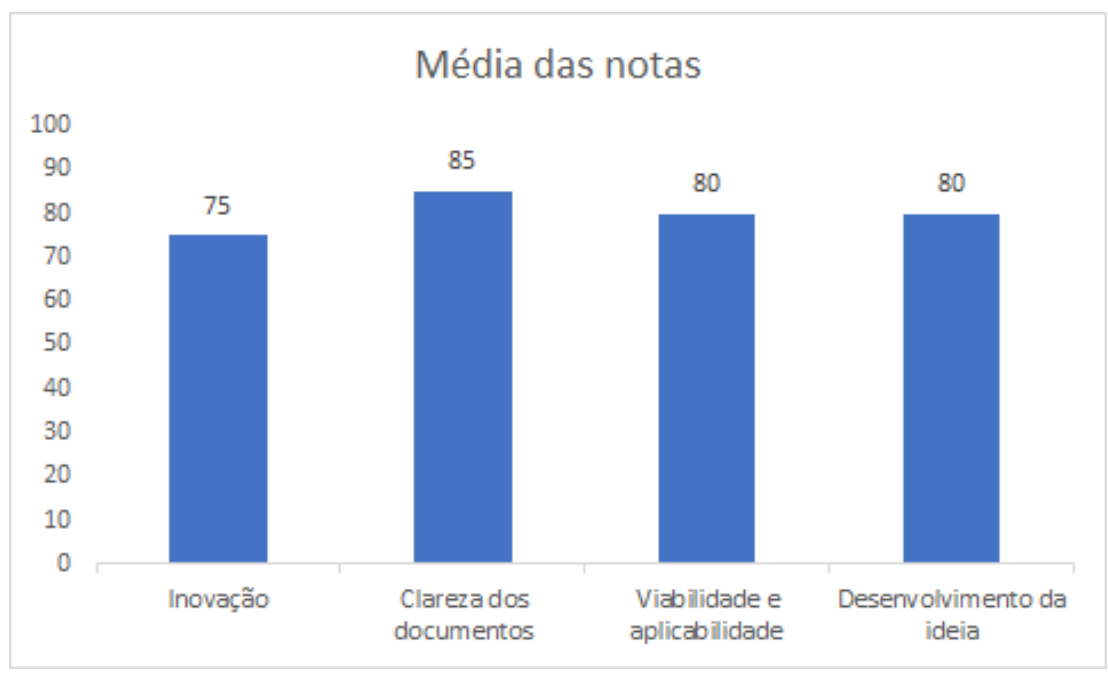

Fonte: Próprio autor 2021

As equipes receberam individualmente um feedback com as sugestões e comentários deixados pelos avaliadores, o que contribuiu ainda mais para a implementação dos projetos. Além disso, todos os trabalhos foram disponibilizados a quem quiser acessálos através de link disponível nas redes sociais, tornando-os de fácil acesso a todos os Ramos Estudantis do Brasil.

O resultado do HackaHome sugere também as temáticas de projetos que podem ser mais viáveis e bem sucedidos neste tipo de contexto, como pode ser conferido pelo Gráfico 2.

Gráfico 2 - Temáticas dos projetos submetidos

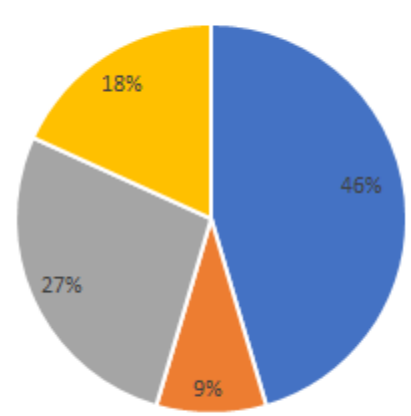


A atividade foi uma oportunidade de networking e aprendizado. Os feedbacks para todos os projetos submetidos foram incentivadores para aprimorá-los e aplicá-los nos Ramos, aumentando o impacto positivo dentro e fora do IEEE. Exercitou-se a criatividade e a escrita de projetos nos participantes. A mentoria de carreira da equipe vencedora foi um aliado no desenvolvimento profissional em seus desenvolvimentos.

\section{CONSIDERAÇÕES FINAIS}

Devido à situação atual imposta pela crise do novo coronavírus, grande parte dos ramos IEEE do país se encontravam com as atividades paralisadas, e alguns já buscavam algum tipo de solução para voltarem a operar. Através da iniciativa HackaHome, equipes de diversas regiões do Brasil tiveram a oportunidade de se concentrar em encontrar tais saídas para sua situação. Um ponto que se pode destacar foi a disponibilização dos papers após a etapa final de entrega dos projetos, possibilitando que todos os participantes tivessem acesso aos trabalhos desenvolvidos durante o evento de modo que eles pudessem servir de inspiração para que iniciativas parecidas fossem replicadas em suas próprias comunidades.

Um dos destaques da atividade é o "KidSTEM", criado por uma equipe do IEEE UFF durante o HackaHome, com o objetivo da criação de um e-book para estimular o interesse e a habilidade de crianças na área STEM (Science, Technology, Engineering and Mathematics) por meio de atividades manuais que podem ser feitas com materiais de baixo custo e facilmente encontrado nas casas das pessoas. Foi aplicado efetivamente após o HackaHome e, no mesmo ano, foi premiado no Brasil e na América Latina como Caso de Sucesso.

Outro projeto destaque, criado durante a atividade, foi o "Assistência Estudantil IEEE UFSJ", por uma do recém-inaugurado na época, Ramo Estudantil IEEE UFSJ. Com a proposta de produzir conteúdo para o vestibular com videoaulas e aconselhamento profissional totalmente gratuito, o projeto foi executado logo após o evento e é realizado até hoje. O projeto ampliou-se com uma parceria com alunos e professores da UFJF e como uma atividade oficial de extensão de ambas as universidades.

Por fim, pode-se concluir que o objetivo do HackaHome foi atingido com êxito, uma vez que em pouco tempo, ideias e iniciativas desenvolvidas durante a competição saíram do papel e foram postas em prática.

\section{Agradecimentos}

Agradecemos aos professores Luis Henrique Lopes Lima, Bruno Henrique Dias, Leonardo Willer de Oliveira por todo apoio. Além disso, a Seção Minas Gerais do IEEE e o Conselho Brasil do IEEE pelo suporte de sempre.

\section{Referências}


Hackathon Brasil, Home. Disponível em:https://hackathonbrasil.com.br/home/o-que-e-hackathon/ .Acesso em 24 abr. 2021.

IEEE.Message from IEEE on coronavirus COVID-19. Disponível em: https://www.ieee.org/about/news/2020/message-on-covid-19.html.Acesso em: 24 abr. 2021. Ramo Estudantil IEEE UFJF. Home - HackaHome IEEE. Disponível em: https://attend.ieee.org/ufjfhackahomel .Acesso em: 24 de abr. de 2021.

Secretaria de Estado de Saúde de Minas Gerais. Entenda a importância do distanciamento social. Disponível em: https://coronavirus.saude.mg.gov.br/blog/108-distanciamento-social . Acesso em: 24 de abr. de 2021.

UFJF. UFJF suspende atividades presenciais nesta terça mantendo somente serviços essenciais. Disponível em: https://www2.ufjf.br/noticias/2020/03/16/ufjf-suspende-atividades-presenciaisnesta-terca-mantendo-somente-servicos-essenciais/. Acesso em 24 de 2021.

\section{HACKAHOME COMPETITION BETWEEN IEEE STUDY BRANCHES FOR PROJECTS WITH SOLUTIONS FOR TRANSITIONING THE PRESENTIAL APPLICATION TO THE REMOTE DURING THE SOCIAL DISTANCING}

Abstract: The HackaHome activity, developed by the IEEE UFJF Student Branch, emerged as an alternative method to the development of projects carried out by IEEE Student Branches of the Brazil Council that had to adapt to the social distance scenario due to the Covid-19 pandemic. HackaHome appears as an attempt to disseminate ideas that can assist IEEE volunteering activities in Brazil even in unstable times.

Keywords: Hackathon. IEEE. Development of solutions. Remote scenario. 